\title{
Routine Seismic Hazard Assessment in Some South African Mines
}

\author{
G. van Aswegen ISS International Limited, South Africa
}

This paper presents a review of seismic hazard assessment methods found useful at a number of gold and platinum mines in South Africa. Long-terms hazard assessments are generally based on numerical modelling of planned mine layouts. Back analyses that allow calibration through correlation with seismicity add confidence to these assessments. Combinations of quantitative and statistical seismicity parameters are proving useful for medium-term (monthly) seismic hazard assessment. One particular approach yields a 'stiffness diagram' on which parameters relating to the loading system softnesses of seismogenic volumes or structures are plotted against parameters relating to the seismic source stiffnesses. The relative seismic hazard increases with an increase in loading system softness and seismic source stiffness.

Short-term seismic hazard assessment (days) involves time history analyses of seismicity parameters for the timeous detection of unstable rockmass behaviour. A representative case shows a tenfold increase in probability of occurrence of a potentially damaging event under 'flag up' conditions compared to 'flag down' conditions. Typically, under 'flag up' conditions such probability is between $20 \%$ and $30 \%$ while under 'flag down' conditions the probability is < $5 \%$.

The normalisation of seismic response with production is vital for the interpretation of seismicity patterns. Calibrated numerical models are good for estimating the effect of particular mining steps. The future of medium-to short-term seismic hazard assessment in mines will involve some form of the integration of numerical modelling with seismic monitoring. One example case shows how excess shear stress (ESS) on a fault close to an advancing longwall face is regularly removed by small seismic events. At one stage, however, the ESS increased after such integration - this circumstance was followed by a large, damaging event.

\section{INTRODUCTION}

This paper presents a summary of seismic hazard assessment methods found useful by the author and his colleagues. The methods are used as part of a commercial service to a number of gold- and platinum mines in South Africa. Some of the methods are described in greater detail in the proceedings of a series of international conferences in South Africa in 2003 (van Aswegen and Laas, 2003; van Aswegen, 2003a, van Aswegen, 2003b).

Modern seismic monitoring systems generate seismological data at an impressive scale with many systems recording hundreds of events per day. The seismic data is gathered for rock engineering purposes and the analyses output should be focussed on information that add value to the economical and safe mine operation. The specific objectives for seismic monitoring may vary - the focus here is on routine hazard assessment for risk management purposes.

It is practical and convenient to consider hazard assessment in the long- medium- and short-terms. The descriptions of methods below are thus subdivided.

\section{DEFINITIONS}

The definitions of seismic event parameters and seismicity parameters commonly used in South Africa and used in this text, but possibly unknown to some readers, may be found in the proceedings of RaSiM5 (Mendecki and van Aswegen, 2001). Because of its specific relevance to this paper, however, descriptions of some parameters are appropriate here.

\subsection{Hazard Magnitude}

One of the problems with quantifying seismicity for a given volume over a given time span lies in the basic nature of large event recurrence: seismicity tends to be intermittent in time and space. Small changes in the spatial or temporal selection boundaries can cause major differences in the quantification of seismicity for a given selection. This is because, for a given selection, the greatest contribution to the total seismic energy release or the total co-seismic strain, as reflected by seismic moment, could come from the one largest event - the inclusion or not of such an event could cause a difference of close to an order of magnitude to the sum of radiated seismic energy and sum of moment.

To overcome this problem, statistical smoothing is required. This can be done following the 'hazard magnitude' procedure. It is based on the standard Gutenberg-Richter (G-R) analysis. Knowing the $a$ and $b$ values of G-R-fit, it is trivial to calculate the numbers of events in each say 0.1 magnitude bin between a given minimum magnitude $m_{d}$ and $m_{\max }$. Using moment magnitude, the seismic moment for each of these magnitude bins is known and the total sum of moment between the $m_{d}$ and $m_{\max }$ can be calculated. Let's call this $\Sigma M_{h}$. We generally use magnitude 1.0 as the value for $m_{d}$ because significant damage can occur with events $\geq$ this magnitude. For data sets of smaller events, however, any value can be used, as long as it is held constant for different time- or space selections for a given study.

Knowing the magnitude- and the E-M relations

$$
\begin{gathered}
\text { magnitude }=\mathrm{A} \cdot \log (M)+\mathrm{B} \cdot \log (E)+\mathrm{C} \\
\log (E)=d \cdot \log (M)+c
\end{gathered}
$$

where $M=$ seismic moment [N.m], $E=$ radiated seismic energy [J] and A, B, C, $c$ and $d$ are constants empirically defined, allows also the calculation of $E$ for each of the magnitude bins and thus the sum of $E$ between $m_{d}$ and $m_{\max }$. Let's 
call this $\Sigma E_{h}$. Knowing $\Delta T$, the time span of the data, we can now normalise these sums to get the equivalent sums for one year periods, $\Sigma M_{h n}$ and $\Sigma E_{h n}$ and define hazard magnitude as

$$
\text { hazard magnitude }=\mathrm{A} \cdot \log \left(\Sigma M_{h n}\right)+\mathrm{B} \cdot \log \left(\Sigma E_{h n}\right)+\mathrm{C} \text { [3] }
$$

This allows the seismic hazard to be expressed as a single number and is useful for hazard ranking between different areas on the same mine (see below).

\subsection{Potential Damage Volume (PDV)}

A further enhancement of the above concept is to translate the impact of seismicity into strong ground motion parameters. The real seismic hazard in mines is, after all, the associated ground shaking.

Stress drop is a direct measure of the slip velocity in the seismic source as follows:

$$
\mathrm{SV}=\beta / \mu \cdot \Delta \sigma
$$

where $S V$ is slip velocity, $\beta$ is the shear wave velocity, $\mu$ is the shear modulus and $\Delta \sigma$ is stress drop (Brune, 1970).

Assuming a) a simple $1 / \mathrm{R}$ drop in velocity of ground motion outside the source, $b$ ) apparent volume a reasonable estimate of source dimension and c) apparent stress proportional to stress drop, the velocity of ground motion $V$ may be estimated from

$$
\begin{aligned}
& V \quad=\quad\left(q^{\bullet} \sigma_{A} \bullet\right) / \mu \quad \text { if } R \leq r_{V a} \\
& \left(q \bullet \sigma_{A} \bullet \beta\right) / \mu \bullet r_{V a} / R \quad \text { if } R>r_{V a}
\end{aligned}
$$

where

$\sigma_{A}-$ apparent stress

$q$ - the empirical ratio $\Delta \sigma / \sigma_{A}$

$R$ - distance from hypocentre

$r_{V a}-$ radius of apparent volume

Setting a lower limit to velocity of ground motion that could cause damage $(V d)$ and then solving for $R$ in $4 \mathrm{~b}$, one can estimate the volume of ground potentially shaken to a damaging level by a seismic event. Knowing $E$ and $M$ for the average event in each magnitude bin used during the calculation of hazard magnitude, such a potential damage volume for each average event multiplied by the number of such events in each bin and then summed over all magnitude bins from $m_{d}$ to $m_{\max }$ is then the potential damage volume.

\subsection{Parameters from the E-M relation}

For a given slope $d$ of the E-M relation, the constant $c$ relates to the level of stress (e.g. Mendecki, 1993). By choosing an average value of $M$ for a given data set and finding the equivalent average $E$ via the E-M relation, an 'average apparent stress' value can be estimated - we call this 'apparent stress level' $\left(\sigma_{A L}\right)$ :

$$
\left[\sigma_{A L}(c)\right]_{d, M \text { constant }}=(\mu / M) 10^{(c+d \log M)}
$$

To compare the $\sigma_{A L}$ amongst a number of sites one has to find the average $d$ value for all the data (we use an orthogonal fit procedure, since both $\mathrm{M}$ and $\mathrm{E}$ are equally variable) and then, using this average $d$ as a constant, solve for $c$ for each individual area of interest.

A good example of the application of apparent stress level was recently presented by Naicker (2003). He showed how this parameter increased with the depth of mining. Although an increase of stress with depth is obvious, it is less obvious that the shear stress required for the dynamic shear failure of rock will increase with the depth of mining. The analysis involved the selection of seismic events $>$ moment magnitude 1 from several mines in the Far West Rand mining district. The mines all have dipping ore bodies, so the data could easily be divided into deeper and shallower sets for each mine. These data sets were then statistically analysed and, amongst others, apparent stress level was calculated.

\begin{tabular}{|c|c|c|c|c|c|}
\hline 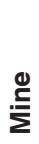 &. 들 & 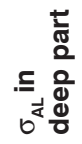 & $\stackrel{\text { 을 }}{\underline{\Sigma}}$ & 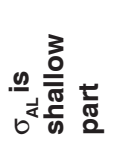 & 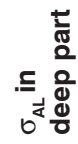 \\
\hline 1 & 486 & 770 & 4 & 301 & 463 \\
\hline 2 & 270 & 373 & 5 & 378 & 390 \\
\hline 2 & 270 & 373 & 6 & 485 & 707 \\
\hline 3 & 438 & 481 & 8 & 291 & 1084 \\
\hline
\end{tabular}
The results are shown in Table 1. The increase in apparent stress level is consistent with other results, e.g. an increase in median apparent stress with depth.

TABLE 1 Apparent stress level and depth of mining

The $\mathrm{d}$ value, or slope of the E-M relation, is considered to reflect local seismic stiffness (e.g. Mendecki et al., 1999). Apparent stiffness is defined as $K_{A S}(d, c)=G\left(E_{2}-E_{1}\right) /\left(M_{2}\right.$ $-M_{1}$ ) where $E_{2}$ and $E_{1}$ are the typical values of $E$ for the two values of $M, M_{2}$ and $M_{1}$. For $K_{A S}$ a moment range $M_{2^{\prime}} M_{1}$ is chosen which spans the bulk of the data.

A good correlation between general rockmass strength (as measured by fault frequency) and apparent stiffness, as described elsewhere (van Aswegen and Laas, 2003) supports the notion that apparent stiffness is a measure of the average source stiffness

NOTE: When calculating the E-M relation and its derived parameters, it is important to filter out the 'A type' events, related to tensile fracturing and/or blasting close to mine openings, from the 'B type' events with simple shear mechanisms - see Richardson and Jordan (2001, 2002). Seismic hazard is here considered to be associated with 'B types' only.

\section{LONG-TERM SEISMIC HAZARD ASSESSMENT IN MINES}

\subsection{General}

Long-term here refers to the time span that would allow changes in mine design. Most mines rely to a large extent on numerical modelling to design mine layouts that minimise the seismic hazard. The usefulness of seismic systems here is that they provide information for the calibration of the numerical models.

When a numerical model is regularly updated and recalibrated as mining progresses, one may refer to 'routine, long-term seismic hazard assessment'. This is a clear goal for mines that take the seismic hazard seriously.

\subsection{Calibration of Numerical Models}

The application of numerical modelling for mine planning is a basic procedure in most deep level mines. Where several years of mining history and seismic data are available, the model can be fine-tuned for the particular circumstance. Calibration of the model output against seismic data through extensive back-analyses alleviate to some extent the fundamental problems associated with all the geotechnical unknowns (details of rockmass characteristics and stress regime).

Numerical models provide several outputs that can relate to seismic hazard. In the South African mining industry Energy Release Rate (ERR) and Excess Shear Stress (ESS) are mainly used (e.g. Ryder and Jager, 2002). Van der Heefer and O'Connor (1994) presented one of the first real applications of numerical modelling to asses quantitatively the seismic 
response to mining and adapting mine design accordingly. Lachenicht (2001) showed that, in a more general approach, where the problem addressed is wider than the specific surrounds of the stope face, 'Volumetric Energy Release' (VER, Wiles, 1998) is a useful parameter for correlating with seismicity. Because of the statistical smoothing involved in its estimation, $\Sigma M_{h}$ (see above) is good for the calibration of numerical models (Fig. 1)

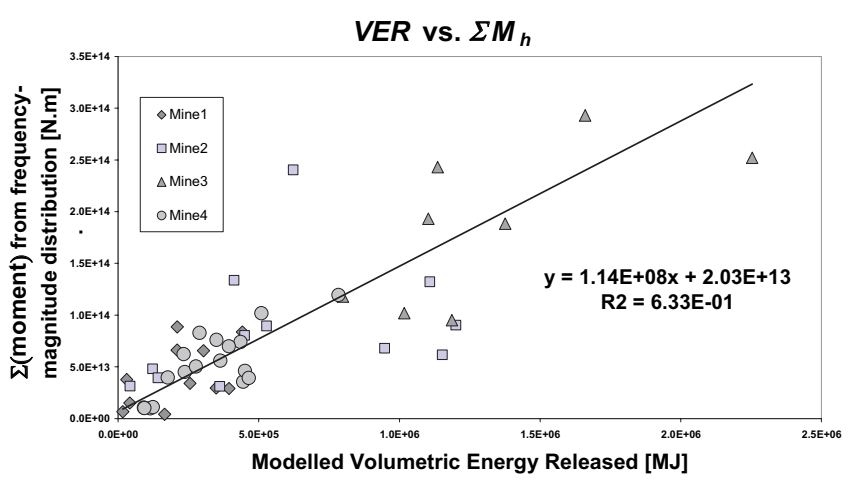

FIG. 1 Modelled VER (Wiles, 1998) vs. the sum of seismic moment ( $\Sigma \mathrm{M}_{\mathrm{h}}$ from the hazard magnitude procedure) for a number of cases under variable mining conditions in South African gold mines (from van Aswegen et al., 2000)

\section{ROUTINE MEDIUM-TERM SEISMIC HAZARD ASSESSMENT}

\subsection{Genera}

The time span for 'medium-term' is here taken as one month this fits in with the monthly planning cycle at the mines. Back analyses of seismicity on a monthly basis have value where the mining environment does not change significantly over such time spans.

\subsection{Spatial Analyses in the Medium-Term}

For the recognition of potentially unstable structures, geological (faults, dykes) or man made (abutments, pillars etc.), the spatial association of seismic events is obviously interpreted at all time ranges of hazard assessment. In a more advanced form of spatial analysis, seismicity contours that relate to strain in the long-term are compared with those that relate to stress in the short-term. Typically, contours of energy index $(E I)$ or apparent stress $\left(\sigma_{A}\right)$ for the past month are superimposed on contours of cumulative apparent volume $\left(\Sigma V_{A}\right)$ or seismic Deborah number $\left(D e_{S}\right)$ based on events over a longer period. Sophisticated 3D contouring methods have been described at RaSiM4 (Funk et al., 1997), but since the ore bodies we deal with are generally planar, 2D contours 'on reef' are more practical for routine work in our case. We prefer contours of long-term 'seismic displacement' (Hofmann et al., 2001) and a plot of recent seismic events with symbol size reflecting $\sigma_{A}$ or EI. (Fig. 2).

The idea is to recognise and delineate sites in the rockmass where seismic strain is lagging and stress has built up - the 'asperity' model for spatial detection of potential instabilities. Fig. 2 demonstrates an example case where, prior to a large event on a dyke, the hypocentral region was characterised by low historic seismic strain (seismic gap) surrounded by small events of relatively high EI. Here a seismic gap does not necessarily mean an area of no seismicity, but rather an area of low historic seismic strain adjacent to- or surrounded by region(s) of high historic strain.

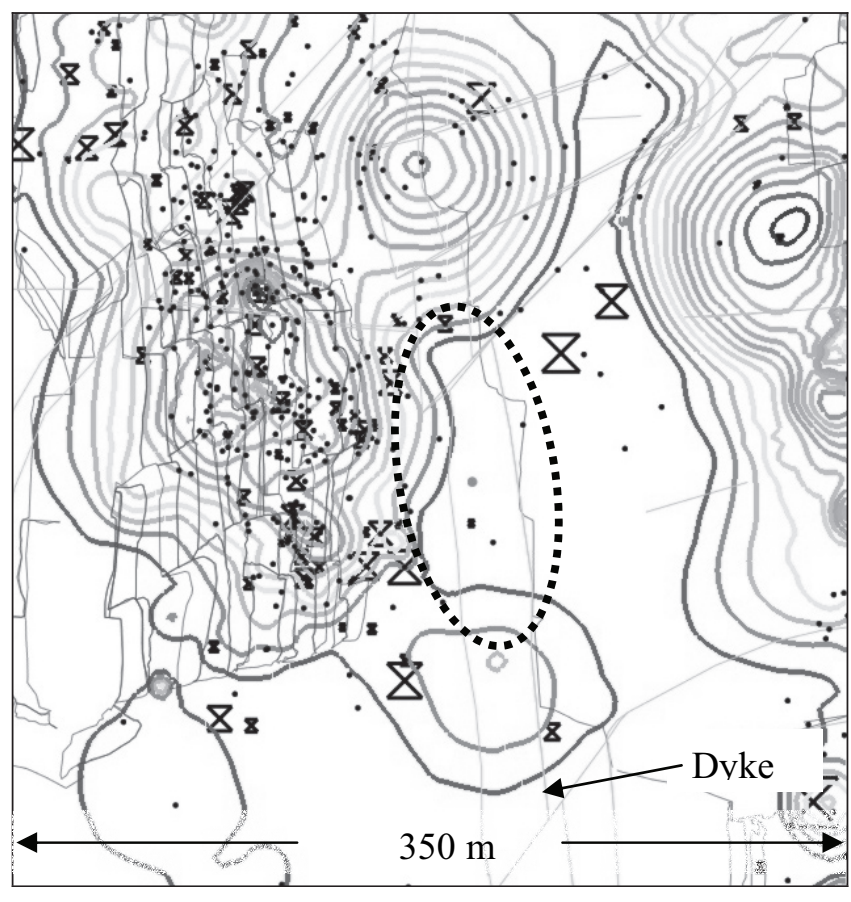

FIG. 2 Contours of seismic displacement, based on $\sim 500$ days of seismicity, delineate a seismic gap. Seismic events during the last 50 days prior to a magnitude 3 tremor (broken line ellipse) are shown as dots and those of them with $\mathrm{EI} \geq 1.5$ are shown as hourglass symbols, the symbol sizes proportional to EI

\subsection{Statistical and Quantitative Analyses}

\subsubsection{Clustering}

Although 'clustering' is a 'spatial' parameter, the result of its quantification is a number - useful to graph with other seismic hazard parameters. Clustering is obviously important - a high degree of clustering could indicate an advanced state of preparation for breakdown instability. In this regard it is important to separate those small events directly related to blasting ('A types') from that population of events that represent the real hazard (the 'B types') - see above.

Because the numbers are easy to handle statistically, there are many clustering algorithms proposed by different authors. One method we use can be considered a bit more 'physical' than 'statistical:- for a given volume of interest, the total volume 'touched' by seismic events is compared to the sum of apparent volume $\left(\Sigma V_{A}\right)$ of the events. The space 'touched' is the sphere around the hypocentre with volume equal to $V_{A}$. Repeated touching of the same volume does not increase the total volume touched, i.e. if a $2^{\text {nd }}$ event of the same $V_{A}$ occurs at exactly the same location as a $1^{\text {st }}$, the total volume touched is unchanged by the $2^{\text {nd }}$ event - the $\Sigma V_{A}$ has, of course, increased by the $V_{A}$ of the $2^{\text {nd }}$ event. The ratio of $\Sigma V_{A}$ to the total touched volume is then a measure of clustering.

\subsubsection{Cumulative seismic moment and cumulative radiated seismic energy}

The most basic quantitative seismicity parameters, for a given volume over a given time span, are the sums of seismic moment and radiated seismic energy. These numbers are also the bases for several derived seismicity parameters (Mendecki, 1997).

A first step in the analysis of a number of production areas on one mine is to simply plot the $\log$ (sum moment) against the $\log$ (sum energy) - the 'cumulative' version of the E-M relation (Mendecki and van Aswegen, 2001). Such a graph is useful since it allows an immediate rating of the different sites 
in terms of seismic hazard and it indicates differences in the nature of seismic response to mining for the different sites. An example is shown in Fig. 3. In this figure, seismic hazard increases from the bottom left to the top right. In the case of two working places with about the same sum of moment, the one with a higher sum of energy would experience, in general, higher stress drop (more damaging) events. $P D V$ is used for the symbol labels and sizes.

More general hazard ranking plots combine conventional hazard assessment and aspects of the source characteristics. Ideally, a 'stiffness' diagram, with loading system stiffness decreasing along the $x$-axis (or softness increasing) and seismic source stiffness increasing along the $y$-axis would present the perfect hazard ranking, with seismic hazard increasing from bottom left to top right. By analogy to a rock testing experiment, the energy release at failure is at a maximum when the loading system stiffness is low and the sample stiffness high. We use apparent stiffness, $K_{A S}$ as a measure of the seismic source stiffness and hazard magnitude as a substitute for loading system softness. An example is shown in Fig. 4. The same data and symbols are used as in Fig. 3.

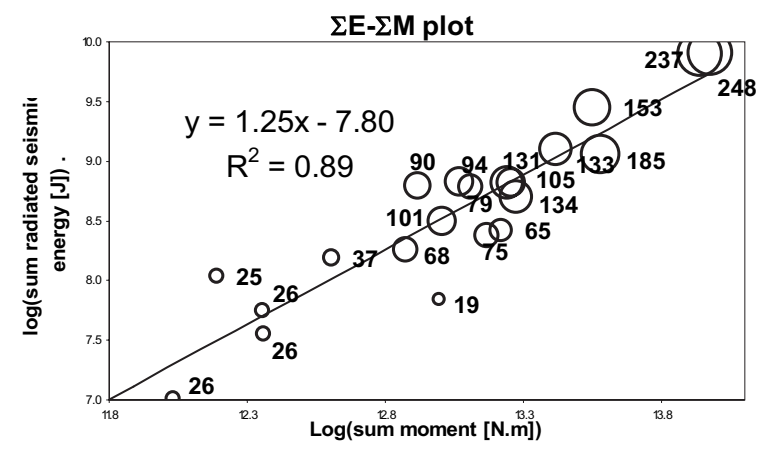

FIG. 3 A 'cumulative' E-M plot for a number of working places at one mine. The data points are and symbol sizes reflect potential damage volume

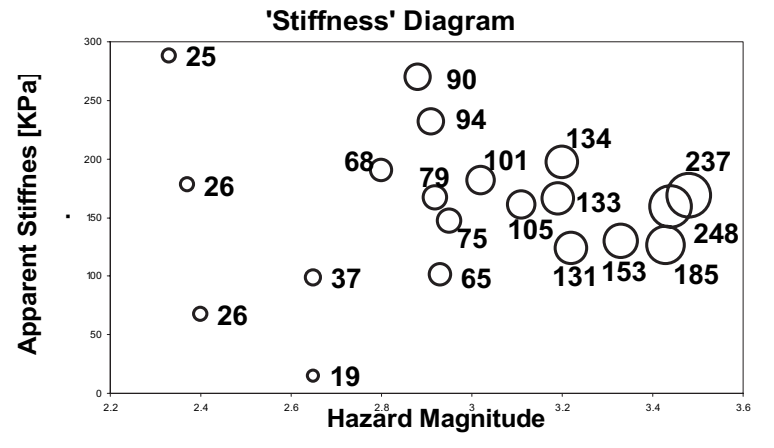

FIG. 4 The same data as in Fig. 3 shown on a 'stiffness' plot

Fig. 4 shows a number of data points with approximately the same hazard magnitude, but separated by apparent stiffness and $P D V$, allowing more detailed hazard ranking.

\subsubsection{Time-of-day distribution}

It may seem obvious, but it is important to analyse how seismic events are distributed during the day. In the back analysis of the 1999 Matjhabeng earthquake in the Welkom gold field (Free State Province, South Africa) it was found that a random time-of-day distribution of seismic events, triggered by mining close to major fault, was indicative of the structure's readiness to yield. The stoping activity served as a 'tap test' and the fault responded anomalously. Seismic events triggered by mining elsewhere on the same mine showed the typical frequency peaks associated with blasting time (van Aswegen, 2001a).

By comparing the time-of-day distribution of mine workers in seismic hot spots with the seismic time-of-day distribution allows seismic exposure to be quantified (van Aswegen, 2001b).

\section{ROUTINE SHORT-TERM SEISMIC HAZARD ASSESSMENT}

\subsection{General}

Short-term here refers to hours and days. Mine seismic systems in many South African mines are manned 24 hours/day, 7days/week and information about the locations and magnitudes of potentially damaging events is available within seconds of such occurrences. This has value to direct the mine's response, e.g. to guide rescue operations. Obviously, however, mine management would prefer to be pre-warned of the increased likelihood of such occurrences - this is the goal of short-term hazard assessment.

The principles of the timeous detection of rockmass instabilities have been described in detail elsewhere (Mendecki, 1997). The applications to short-term seismic hazard assessment procedures, as referred to below, have essentially not change since 1995. Success rates vary. In some cases the seismic rockmass response to mining is too fast or too slow for the methods to be useful on a daily basis. Since lives could be at stake, however, we have no choice but to a) keep doing the best we can and b) research methods to improve the success rates.

\subsection{Routine Rating of Seismic Hazard}

The routine, short-term hazard assessment methods being used twice a day at $\sim 100$ areas of interest in mines, are based on cumulative apparent volume $\left(\Sigma V_{A}\right)$ seismic Schmidt number $\left(S c_{s d}\right)$, Energy Index $(E I)$ and activity rate.

Fig. 5 shows an example of a time-history plot of $S c_{s d}$ and $E I$, with the time of occurrence of larger events indicated as bold broken lines at the bottom of the graphs. It shows that a larger event frequently follows a drop in the values of these parameters. Each of seven events $>$ local mag. 1.8 was preceded by a drop in $S c_{s d}$ and there were three (broken line arrows) out of nine false alarms. In the case of $E I$, six of the seven events were preceded by a drop in $E I$ and there were no false alarms. $\Sigma V_{A}$ showed an upswing prior to the large events in only a few cases.

\section{Mine 1: $P($ mag $>=1.5$, rating $>=5)$}

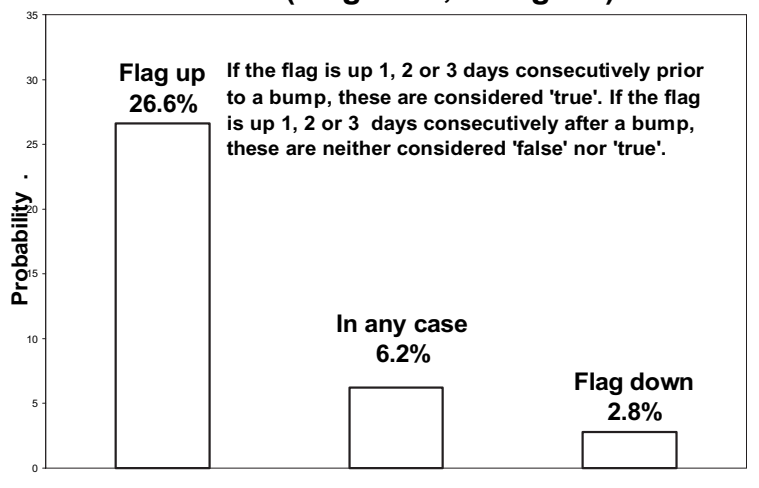

FIG. 6 A typical example of the 'success rate' of routine shortterm seismic hazard assessments at a S.A. gold mine. More than 100 assessments are done per day on a commercial basis 


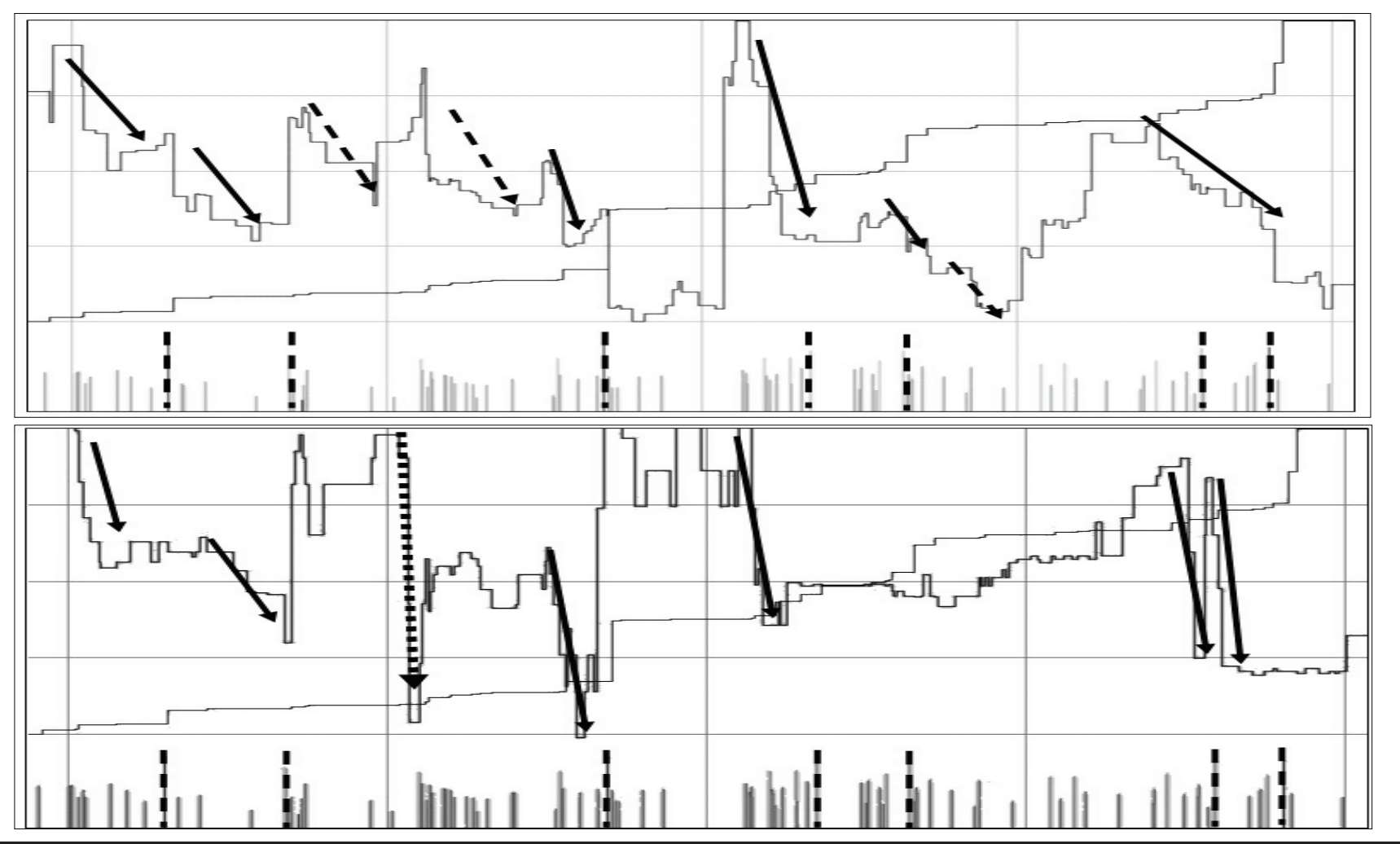

FIG. 5 An example of a time history analysis for a particular production area, showing that seismic Schmidt number $\left(S C_{s d}\right)-$ top - and energy index $(E I)$ - bottom - generally drop prior to larger events. The cumulative graph is that of cumulative apparent volume $\left(\Sigma V_{A}\right)$

Annual back analyses results are provided to the mines for assessment of the success rate of the methods so that risk management procedures can be adapted. Fig. 6 shows the results of one such back analysis for one mine. The particular example is considered a fair average case - in some cases the results show a higher success rate and in others it is worse. We consider a 'flag up' situation where the hazard rating exceeds a particular value and assess the likelihood for a seismic event $\geq$ a given magnitude to occur during the 3 days following the issuing of the rating, i.e. the 'flag up' was 'true'. Note in the example that the probability of a larger event is 10 times greater during 'flag up' conditions compared to 'flag down' conditions. This ratio varies from 3 to 10 times in our experience.

\subsection{Normalising Seismicity with Production}

Comparing seismic response to mine production is essential in the interpretation of seismicity patterns. Since the removal of volumes of rock at depth is the driving force for mine seismicity, one should be able to quantify some balance between production and seismicity. By monitoring the ratio between $\Sigma V_{A}\left[\mathrm{~m}^{3}\right]$ and production $\left[\mathrm{m}^{3}\right]$ against time, one can detect whether the seismicity is 'lagging behind' or 'running away'. This ratio is referred to as SRP, for 'seismic response to production' (Amidzic et al., 1999).

A more robust procedure, based on seismic potency, is described by Mendecki (2005).

\section{THE FUTURE - INTEGRATION OF NUMERICAL MODELLING AND SEISMIC MONITORING}

Probably the best way to account for the relation between seismicity and production is through numerical modelling, since the numerical model has information not only of recent production, but also of the whole mine geometry - it can anticipate the effect of a particular production step. Com- paring such anticipated seismic response to the measured response on a daily basis is the ultimate aim of the integration of seismic monitoring with numerical modelling.

Although the methods have, disappointingly, not become routinely applied in the mining industry since the concept was described in several papers at RaSiM5, a number of quite successful exercises have been concluded.

The particular example described here is from a study at a mine $\sim 100 \mathrm{~km}$ west of Johannesburg. Here the Carbon Leader Reef, that dips $\sim 20^{\circ}$ south, is mined at a depth of $\sim 3000 \mathrm{~m}$ below surface.

A local magnitude 3.2 occurred on a steeply dipping geological structure ahead of a longwall stope. The case was modelled by Hofmann (2003) and the output from that exercise subsequently analysed (van Aswegen, 2003c). A series of monthly mining steps were modelled as the longwall approached the dyke. In each step, the ESS was calculated on the structure and then the seismic events associated with that step introduced in the model and the loading equilibrated. Details of these procedures are given in Hofmann et al., (2001) and Wiles et al. (2001).

The results for each step were that the seismic events 'wiped out' most of the ESS. During the last step prior to the mag. 3.2 event, however, the ESS on part of the structure actually increased after the integration step. This remarkable increase in ESS was exactly in the hypocentral area of the large event that followed.

The last three mining steps prior to the large tremor are illustrated in a series of snapshots of the appropriate part of the model (Fig. 7). For each mining step the ESS induced by the mining is shown, then the distribution of seismic events along the structure and then the new ESS after integration. 

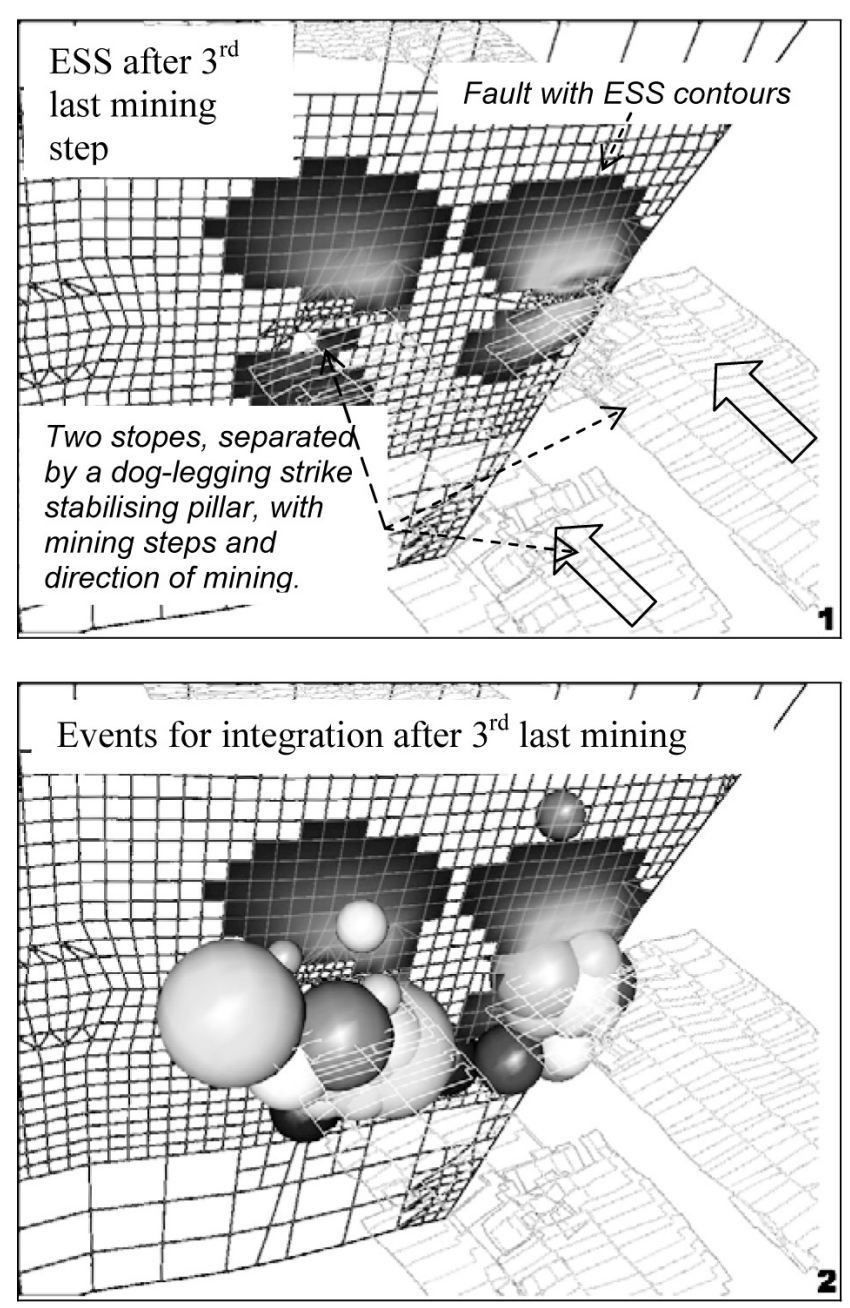
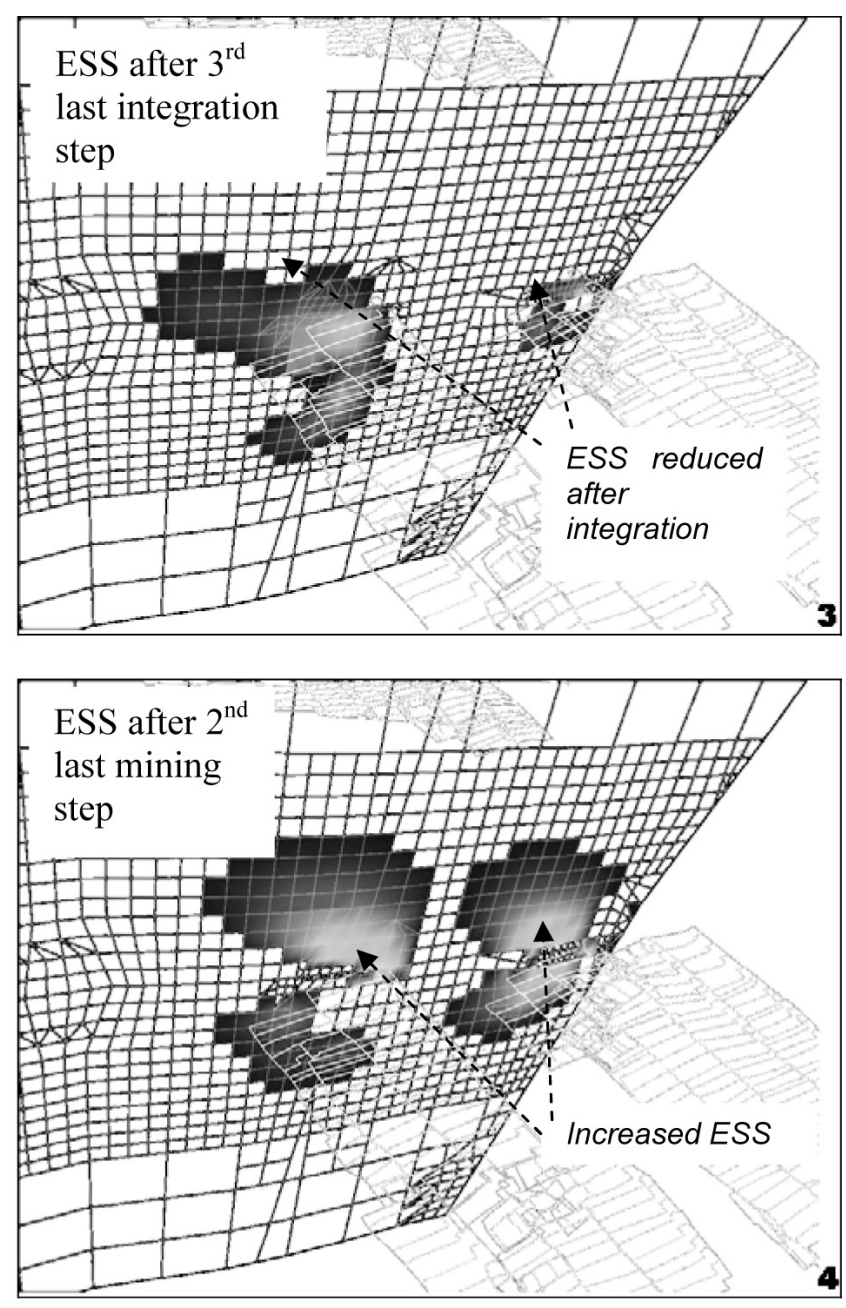

FIG. 7 Numbered snapshots of part of a Map3Di® model, showing the geometry of the last 3 of a series of mining steps (light grey) of a longwall stope along the shallowly dipping Carbon Leader Reef approaching a steeply dipping fault (dark grey mesh). Image 1 shows contours of ESS after the 3rd last mining step. Image 2 shows seismic events (sphere volumes equal to Va). Seismic displacements derived from these events were integrated to yield a lowering of ESS (image 3). The next mining step increased the ESS again (image 4)

\section{CONCLUSIONS}

In South Africa, the seismic monitoring in mines evolved from an esoteric research endeavour to a day-to-day business. Long- medium- and short-term seismic hazard assessment techniques abound, some described here. The success rate of all these methods are not sufficient at this time - fatal accidents are still too numerous. A firm basis does, however, exist to steer research and development towards the full achievement of the objectives of seismic monitoring in mines.

The integration of numerical modelling with seismic monitoring holds particular promise for short-term hazard assessment. Methods based on numerical models that take into account the large and small scale mine geometry plus the short-term loads caused by daily mining and seismicity should be better at assessing short-term stability than methods based on seismic data alone.

\section{ACKNOWLEDGMENTS}

The author is grateful to the South African Institute of Mining and Metallurgy for permission to re-produce Fig. 5 from the proceedings of the $30^{\text {th }}$ International Conference of Safety in Mines Research Institutes - see van Aswegen, 2003b.

Several SIMRAC (Safety in Mines Research Advisory Committee of the Department of Minerals and Energy, South Africa) research projects contributed to the development of seismic hazard assessments method as reflected in the list of references.

The methods described above evolved over years of providing a service to the Rock Engineering staff of AngloGold Ashanti. Their sometimes severe, but generally constructive critique is highly appreciated. 

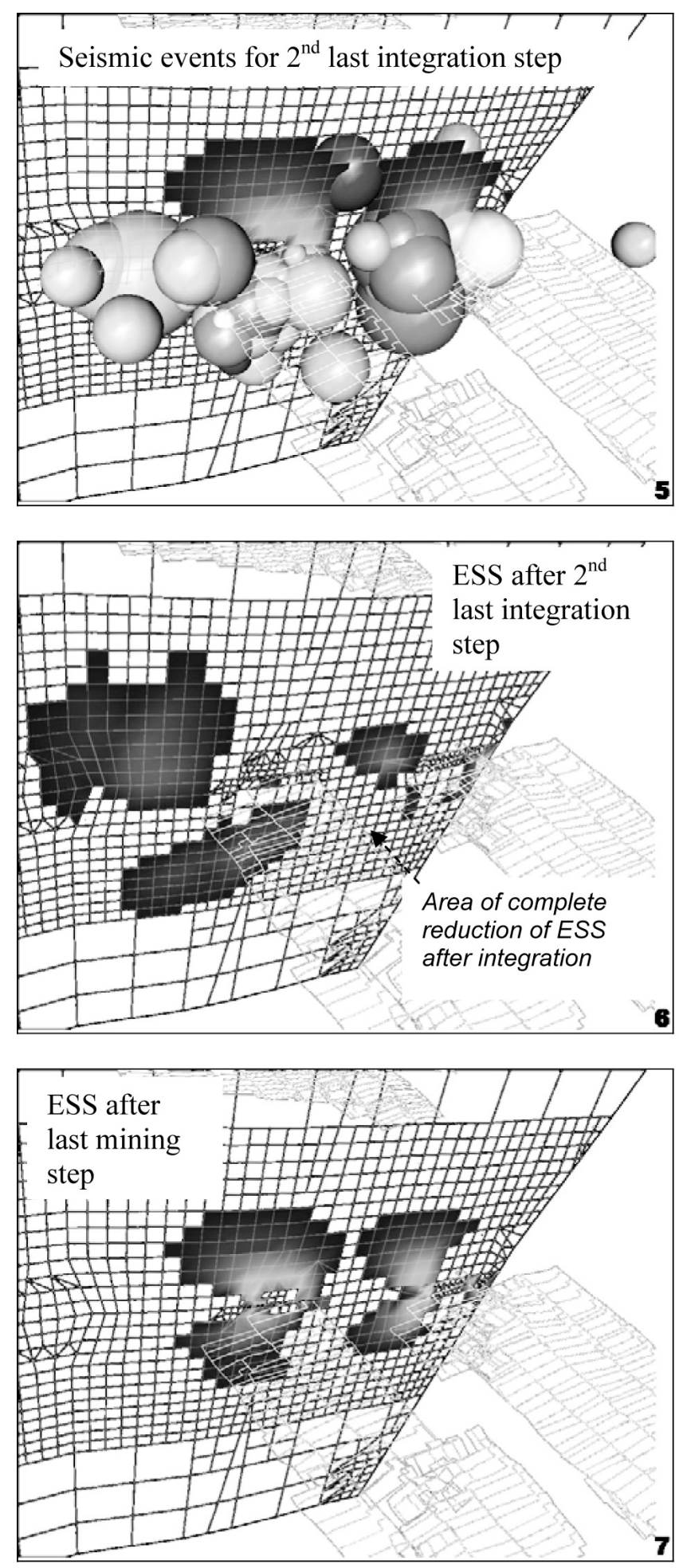
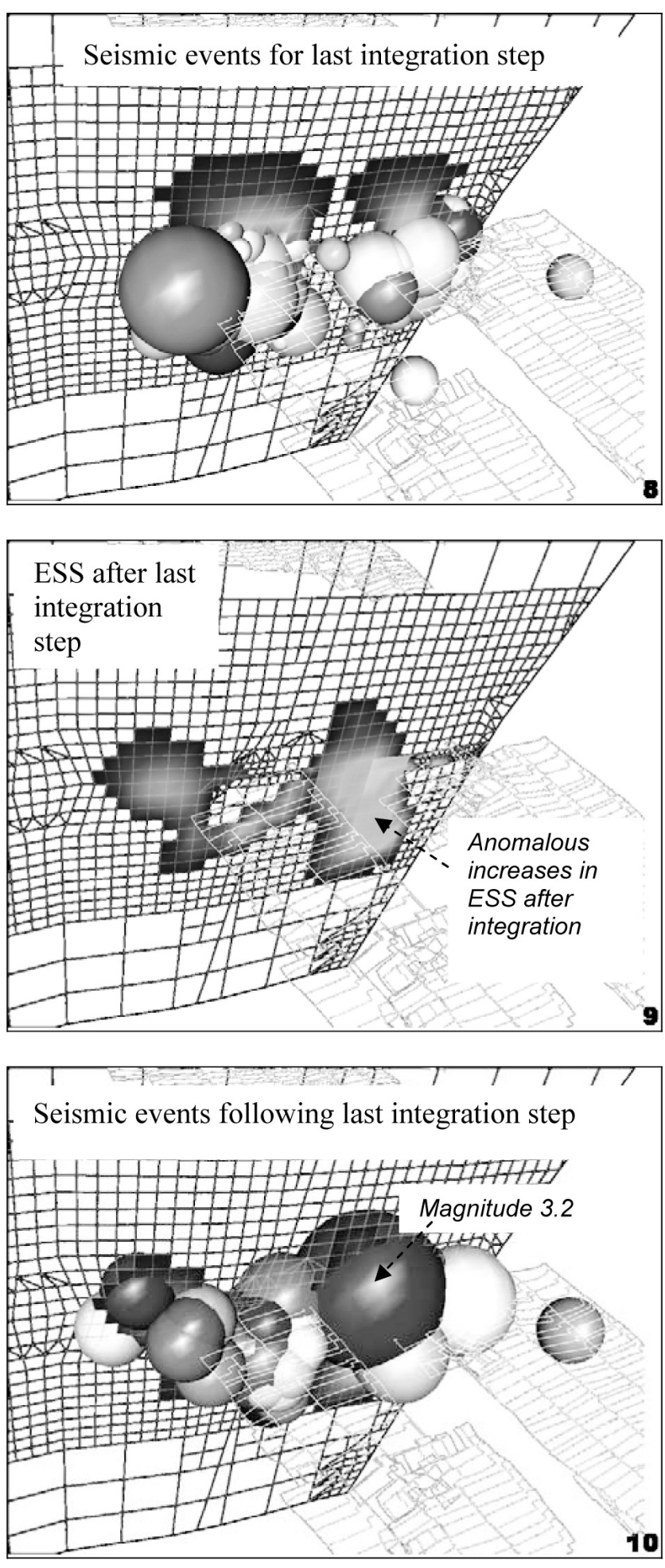

FIG. 7 (continued from previous page) Image 5 shows seismic events integrated after modelling the effect of the 2nd last mining step and image 6 shows the lowering of ESS following this integration. Image 7 shows the ESS after the last mining step, image 8 the events for the last integration step and image 9 the ESS after the last integration step. Here the ESS significantly increased after integration. A local magnitude 3.2 event followed this anomalous phenomenon (largest sphere in image 10) 


\section{REFERENCES}

Amidzic, D., Murphy, S.K. and van Aswegen, G. (1999) Case study of a large seismic event at a South African gold mine. 9th International Congress on Rock Mechanics, ISRM, Paris.

Brune, J.N. (1970) Tectonic stress and the spectra of seismic shear waves from earthquakes. J. Geophys. Res. pp. 75.

Funk, C., van Aswegen, G. and Brown, B. (1997) Visualisation of seismicity. In: Gibowicz SI and Lasocki S (Eds.). Rockbursts and Seismicity in Mines, 4th International Symposium. Balkema, Rotterdam.

Hofmann, G., Sewjee, R. and van Aswegen, G. (2001) First steps in the integration of numerical modelling and seismic monitoring. . In: van Aswegen, G., Durrheim, R.J. and Ortlepp, W.D. (Eds.) Rockbursts and Seismicity in Mines - RaSiM5, South African Institute of Mining and Metallurgy, Johannesburg, South Africa.

Hofmann, G. (2003) Integration for Controlled Mining at Section 336, TauTona Mine. Update for mining 16 Jan 2003 to 15 Feb 2002

Lachenicht, R. (2001) Relationship between ERR, system stiffness parameters and seismic energy release for different geotechnical areas. SIMRAC Final Report GAP612a. Department of Minerals and Energy, Pretoria (http://www.simrac.co.za)

Lachenicht, R., Wiles, T. and van Aswegen, G. (2001) Integration of deterministic modelling with seismic monitoring for the assessment of the rockmass response to mining: Part II Applications. In. van Aswegen, G., Durrheim, R.J. and Ortlepp, W.D. (Eds.) Rockbursts and Seismicity in Mines - RaSiM5, South African Institute of Mining and Metallurgy, Johannesburg, South Africa.

Mendecki, A.J. (1993) Real time quantitative seismology in mines. Keynote lecture in: Young, R.P. (Ed.) Rockbursts and Seismicity in Mines. Kingston, Canada. Balkema, Rotterdam.

Mendecki, A.J. (1997) Seismic Monitoring in Mines. Chapman and Hall, London.

Mendecki, A.J. (2005) Persistence of seismic rockmass response to mining In: Potvin, Y. and Hudyma, M.R., (Eds.) Rockburts and Seismicity in Mines - RaSiM6, ACG, Perth, Australia.

Mendecki, A.J. and van Aswegen, G. (2001) Seismic monitoring in mines: selected terms and definitions. In: van Aswegen, G., Durrheim R.J. and Ortlepp, W.D. (Eds.) Rockbursts and Seismicity in Mines - RaSiM5, South African Institute of Mining and Metallurgy, Johannesburg, South Africa.

Naicker, N. (2003) Seismicity vs. Depth. Unpbl. Presentation at the 13th ISS International Seminar on: Best Practise in Seismic Monitoring and Numerical Modelling for Mining, Stellenbosch, March 2003.

Richardson, E. and Jordan, T.H. (2002) Some properties of gold-mine seismicity and implications for tectonic earthquakes. In van Aswegen, G., Durrheim, R.J. and Ortlepp, W.D. (Eds.) Rockbursts and Seismicity in Mines - RaSiM5, South African Institute of Mining and Metallurgy, Johannesburg, South Africa.

Richardson, E. and Jordan, T.H. (2002) Seismicity in deep gold mines of South Africa: implications for tectonic earthquakes. Bull. Seism. Soc. Am., 92.

Ryder, J.A. and Jager, A.J. (2002) A textbook on Rock Mechanics for tabula hard rock mines. 1st Edition, Department of Minerals and Energy, Pretoria, South Africa.

van Aswegen, G. and Mendecki, A.J. (1999) Mine layout, geological feature and seismic hazard. SIMRAC Final Report GAP303. Department of Minerals and Energy, Pretoria. (http://www.simrac.co.za).

van Aswegen, G., Spottiswoode, S.M. and Naicker, N. (2000) The relationship between depth and seismicity. Final report, Deepmine Project 5.1.1, CSIR Miningtek, Johannesburg.

van Aswegen, G. and Laas, J. (2003) Monitoring the rockmass response to mining in Witwatersrand gold mines. ISSA/Chamber of Mines Conference 2003 - Mines and Quarries: Prevention of Occupational Injury and Disease. Symposium Series S32, South African Institute of Mining and Metallurgy, Johannesburg, South Africa.

van Aswegen, G. (2001a) Analysis of the processes which lead to potentially damaging seismic events associated with geological structures and highly stressed areas in extensively mined areas and old mines. SIMRAC Final Report. GAP605, Department of Minerals and Energy, Pretoria (http:/ /www.simrac.co.za).

van Aswegen, G. (2001b) Evaluation of the risk to underground mine personnel due to the rockmass response to continuous mining operations. SIMRAC Final Report. GAP610, Department of Minerals and Energy, Pretoria (http: / www.simrac.co.za)

van Aswegen, G. (2003a) Seismic hazard assessment methods in mines. 10th International Conference on Rock Mechanics - ISRM2003, South African Institute of Mining and Metallurgy, Johannesburg, South Africa.

van Aswegen, G. (2003b) Towards Best Practice for Routine Seismic Hazard Assessment in Mines. 30th International Conference of Safety in Mines Research Institutes South African Institute of Mining and Metallurgy, Johannesburg, South Africa. van Aswegen, G. (2003c) Towards the best practice in routine and special seismic data analysis and interpretation. Unpbl. Presentation at the 13th ISS International Seminar on: Best Practise in Seismic Monitoring and Numerical Modelling for Mining, Stellenbosch, March 2003.

van der Heefer, P.K. and O'Connor, T.S. (1994) The mining of a stressed deep-level shaft pillar. XVth CMMI Congress, South African Institute of Mining and Metallurgy, Johannesburg.

Wiles, T.D. (1998) Correlation between local energy release density and observed bursting conditions at Creighton Mine. INCO Limited Research Report. Sudbury, Ontario, Canada.

Wiles, T., Lachenicht, R. and van Aswegen, G. (2001) Integration of deterministic modelling with seismic monitoring for the assessment of the rockmass response to mining: Part I Theory. In. van Aswegen, G., Durrheim, R.J. and Ortlepp, W.D. (Eds.) Rockbursts and Seismicity in Mines - RaSiM5, South African Institute of Mining and Metallurgy, Johannesburg, South Africa. 